\title{
High-Resolution Imaging within the Urban Environment- "What's beneath our streets"!
}

As part of the National Earthquake Hazards Reduction Program (NEHRP), detailed seismic-reflection studies (high-resolution imaging) are conducted in urban areas to gather information necessary to assess potential earthquake hazards within communities prone to damaging earthquakes.

\section{Why Work in the Streets and How this Information is Used}

National and regional earthquake hazards maps are critical to effective hazard-mitigation strategies for communities prone to earthquakes. For this reason, NEHRP conducts studies in urban areas to produce hazard assessments that reflect local variations in geology and seismic-wave propagation. The greatest challenge in producing credible and useful regional hazard assessments is reducing modeling uncertainties through more accurate

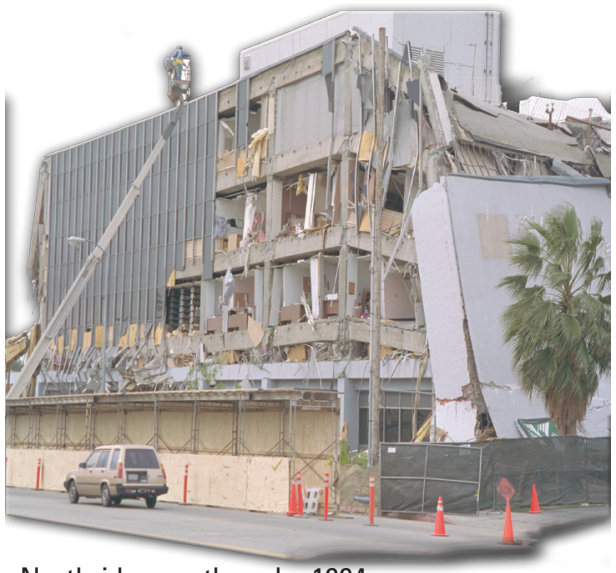

Northridge earthquake 1994 aftermath. Over 60 fatalities and in excess of 20 billion dollars in damage and abundant geological and seismological observations. This pertains particularly to information on where earthquakes originate (source), their size (magnitude) and recurrence time, and site-specific ground-shaking effects. To acquire this information in urban areas, studies are conducted that measure near-surface attributes such as geologic setting, structure, seismic velocity, topography, ground water, and rock properties.

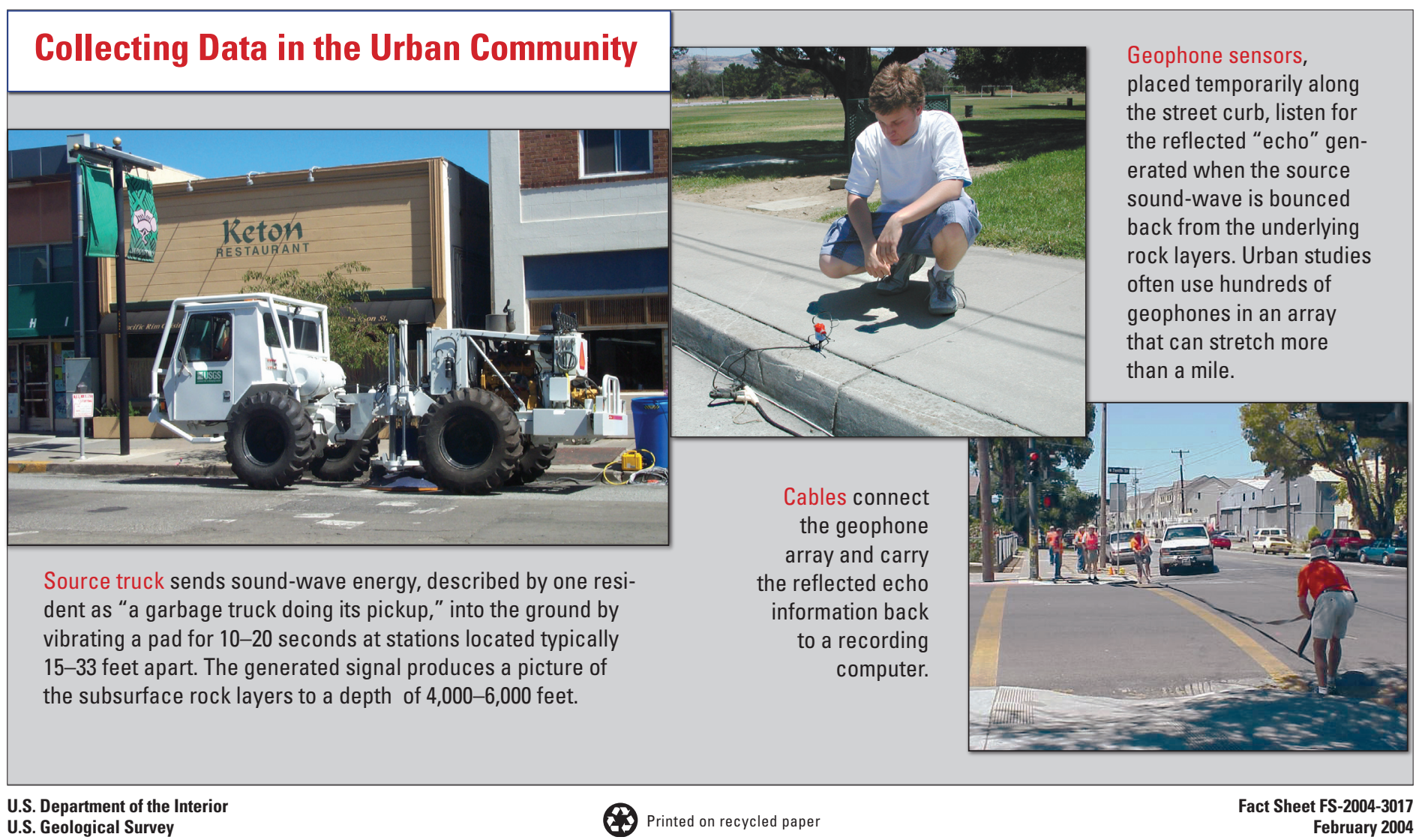




\section{Taking the "Picture" - Beneath the City Streets}

Cities are filled with cultural noises that are caused by traffic, airplanes, and pedestrians within the community conducting activities associated with everyday life. Consequently, acquiring quality information to create a "picture" of what is beneath the streets under these less than ideal conditions (from a seismicimaging viewpoint) is challenging to research scientists.

To meet this challenge, the U.S. Geological Survey has adapted and modified existing equipment and data- acquisition techniques. The equipment used to collect information must be powerful enough for survey needs without damaging streets and nearby structures or disrupting the flow of traffic or pedestrians. The signal-recording equipment (geophone sensors and cables) must be sensitive enough to record the seismic signal over nearly a mile in the noisy city environment without interfering with everyday community activities.

Hundreds of vibration points are integrated to produce a depth crosssection of the rocks beneath a city. Computer processing corrects for elevation changes, bends in line geometry and missing geophones (street crossings). Noise filtering and signal enhancement software is used to remove some of the degrading effects introduced by the everyday background noise.

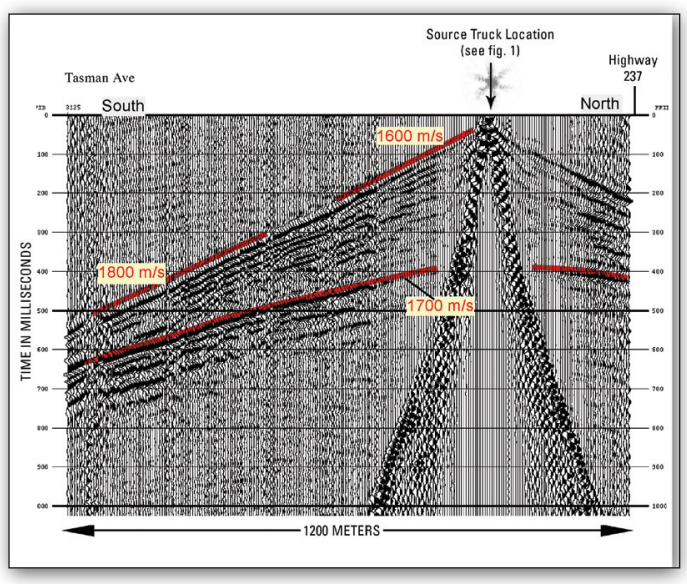

Record produced when the energy source truck vibrates. Each vertical line (squiggle) represents information received from one geophone. The entire record contains information from an array of 240 geophones that are "listening" along nearly 1 mile in San Jose, Calif. The field record is a plot of time (vertical) versus distance (horizontal) for the sound wave to travel to a rock boundary below and return to the surface. The rock layer boundaries appear as heavy, coherent black bands (in the figure, some are highlighted in red).

\section{Using the "Picture"}

$\mathrm{T}$ he subsurface images or "pictures" that result from these studies in the streets of the urban community increase our knowledge of earthquake occurrence, potential earthquake ground shaking, and the geology that commonly controls water flow. From the subsurface "pictures" we are able to see faults and determine if and how they move. These images also help explain why different parts of a city shake more strongly than others and contribute to work that could lead to forecasting future earthquake ground shaking. Also, knowing the position and geometry of faults and the thickness of rock layers and unconsoli dated materials will improve our ability to create ground-water models and, ultimately, lead to better management of the existing water supply.

For more information, contact:

Earthquake Hazards Program

U.S. Geological Survey

Golden, C0 80401

Written by Jackson K. Odum, Robert A. Williams, William J. Stephenson, and David M. Worley

Graphics and layout design by Eleanor M. Omdahl

This Fact Sheet is available online at: http://pubs.usgs.gov/fs/2004/3017/

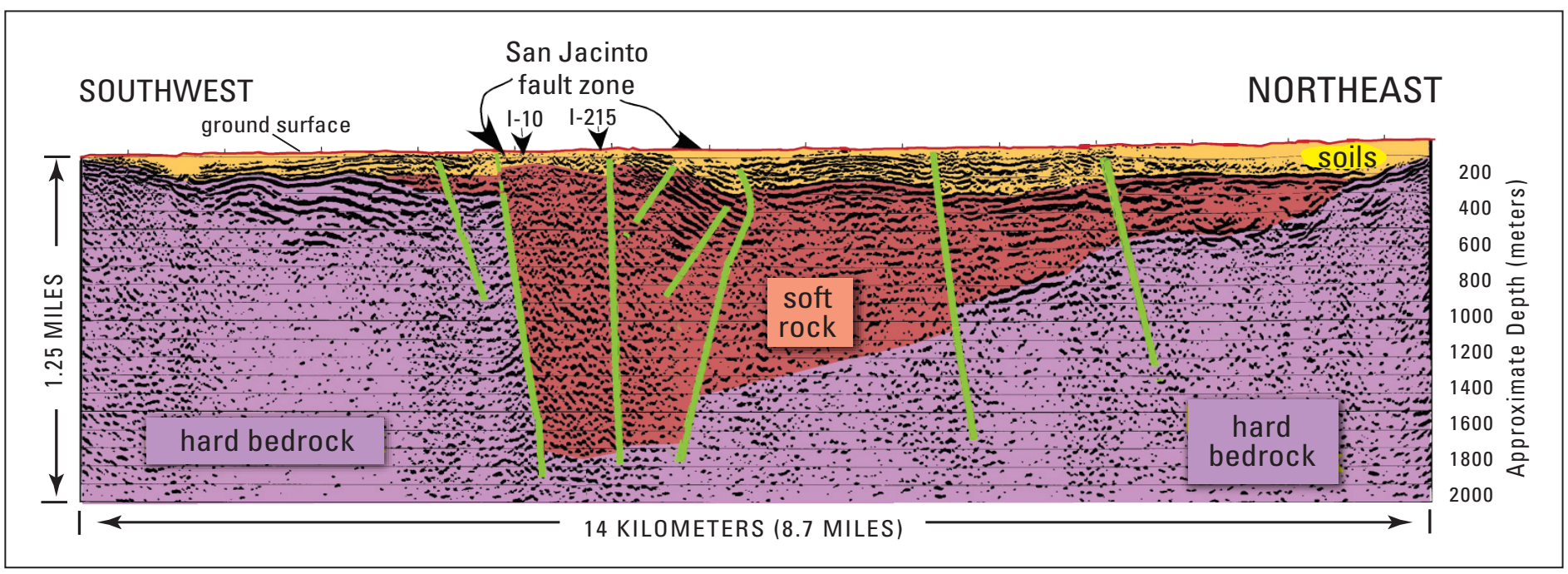

This San Bernardino Basin profile created from hundreds of individual records (such as Record shown above) is an example of a high-resolution seismic-reflection "pict with thick sediments have broken, offset, and folded the underlying rocks. 